\title{
Updating the Atlas of Groundwater Dependent Ecosystems in response to user demand
}

\author{
E.R. Nation ${ }^{a}$, L. Elsum ${ }^{a}$, K. Glanville ${ }^{\mathrm{b}}$, E. Carrara ${ }^{\mathrm{a}}$ and $\underline{\text { A. Elmahdi }}{ }^{\mathrm{a}}$ \\ ${ }^{a}$ Bureau of Meteorology, Victoria \\ ${ }^{b}$ Department of Science, Information Technology and Innovation, Queensland \\ Email: elisabetta.carrara@bom.gov.au
}

\begin{abstract}
In many parts of Australia, there is increasing pressure on water resources from various activities including agriculture, mining, urban and commercial developments. Groundwater dependent ecosystems (GDEs) are vulnerable to altered groundwater regimes including flow, pressure, level and/or quality associated with such activities (Eamus et al. 2006). Understanding their locations and groundwater dependency is essential for the management of GDEs. The Atlas of Groundwater Dependent Ecosystems (the Atlas) is the national inventory of mapped GDEs in Australia. By making data easily available, the Atlas ensures GDEs can be considered in natural resource management, water planning processes and environmental impact assessments.
\end{abstract}

The Atlas was first released on the Bureau website in September 2012. The original data in the Atlas was collected during 2009-10 at the national scale and there has been considerable progress in GDE mapping at the State and regional scale since this time. For example, the Queensland Government has created catchmentscale GDE maps for over half of their State.

Due to an overwhelming request from users and stakeholders, the Bureau of Meteorology has worked with State and Territory water agencies to update the Atlas and maintain its currency. The Atlas has been updated with new regional-scale mapping for parts of New South Wales, Northern Territory, Queensland, South Australia and Victoria. To update the Atlas, the Bureau collated State and regional GDE datasets from a number of agencies for each of the GDE layers: Aquatic, Terrestrial and Subterranean. Coverage was partial for most States, and datasets were created using a range of methods developed for different purposes which are no longer nationally consistent.

To convey information about differences in data source, the attribution of GDEs was updated to clearly distinguish between pre-existing data from the national assessment and new datasets, whilst retaining key national scale information about the GDE potential (the confidence in the identification of an ecosystem as groundwater dependent). New attributes were added to the data model to capture information about the data source. Each dataset required a different approach for integration, and consultation with States and Territories helped in determining this process. The key steps for each State or Territory update were:

1. pre-processing of State and Territory datasets into new data model format

2. attribution of known and potential GDEs according to new rule system

3. mapping of data, which either involved replacing existing data or using precedence rules where overlap occurred

4. populating new data schema using State attributes

5. running Python script to populate national attributes.

In this paper the Queensland Government's GDE data is used as an example of how the Bureau integrated the new State GDE data into the Atlas to ensure that the best available GDE data can be accessed from a central location. Building on the success of the update, the Bureau has established a national GDE Reference Group to continue communication with data custodians, GDE experts and Atlas users. This group will facilitate ongoing access to updated GDE data in order to maintain the currency and relevance of this important product into the future.

Keywords: Groundwater dependent ecosystem, groundwater, geographic information system 


\section{INTRODUCTION}

Groundwater plays an important role in sustaining aquatic and terrestrial ecosystems, such as aquifers, caves, spring ecosystems, lakes, rivers and vegetation. Understanding these groundwater dependent ecosystems (GDEs) is essential for water resources management and planning. The Atlas of Groundwater Dependent Ecosystems (the Atlas) was developed as the national dataset of mapped GDEs to inform groundwater planning and management. It is the first and only national inventory of GDEs in Australia.

The Atlas was originally developed by the former National Water Commission, SKM, CSIRO, Cohga and the Bureau of Meteorology (the Bureau) with considerable input from every State and Territory. The GDE mapping in the Atlas was produced by conducting a national-scale assessment. A nationally consistent methodology used GIS rules-based analysis and remote sensing to map the potential for groundwater/ecosystem interaction (Doody et al. 2017; SKM 2012; SKM and CSIRO 2012).

The Atlas web mapping application was first released on the Bureau website in September 2012. For many years it provided the best available GDE data needed to inform planning, management and research for most of Australia. However, over time some of the data in the Atlas became superseded. The original data in the Atlas was collected during 2009-10 and there has been considerable progress in regional-scale GDE mapping by State and Territory agencies since this time. For example, the Queensland Government has created catchment-scale GDE maps for over half of their State (DSITI 2015). Consequently some former users of the Atlas started to use the new State GDE datasets in preference to the Atlas. For example, ecologists working on the Bioregional Assessment Programme to assess the potential impacts of coal seam gas and coal mining developments on GDEs.

The Bureau also received feedback from users requesting an update to the Atlas. In addition, the Bureau was approached by the Queensland Government to integrate their new data into the Atlas. In response to these requests, the Bureau decided to update the Atlas in 2016-17 using new regional scale GDE datasets in collaboration with State and Territory data custodians. However, new regional dataset coverage was partial for most States, and datasets were created using a range of methods developed for different purposes which were no longer nationally consistent.

This paper describes the work undertaken by the Bureau to update the Atlas including:

- collating new GDE data for parts of New South Wales, Northern Territory, Queensland, South Australia and Victoria;

- standardising the data to the national data model with a new attribution enhanced with further information on the data source, methodology and GDE confidence;

- integrating the new data into the national GDE dataset; and

- publishing the data in the updated Atlas web mapping application.

\section{METHOD}

The first step in updating the Atlas was to simplify the terminology used to describe GDE types to be consistent with international terminology used by Foster \& Tyson (2016). The Atlas currently contains information about the three main types of GDEs:

- aquatic ecosystems that rely on the surface expression of groundwater-including surface water ecosystems which may have a groundwater component, such as rivers, lakes, and spring ecosystems. Marine and estuarine ecosystems can also be groundwater dependent, but these are not mapped in the Atlas.

- terrestrial ecosystems that rely on the subsurface presence of groundwater-including vegetation ecosystems such as forests and riparian vegetation.

- subterranean ecosystems including cave and aquifer ecosystems.

The approach to updating the Atlas was to integrate recent regional scale GDE datasets with the national assessment data already in the Atlas. 


\subsection{Updating the GDE attribution and symbology}

The next step in updating the Atlas was to update the way GDEs are attributed and delivered to users. This enhanced attribution enabled clearer understanding of variations in data source and methodology introduced to the Atlas by incorporating new datasets. The attribution was updated to highlight:

- data source - national assessment or regional studies

- methodology - known GDEs from fieldwork or potential GDEs from desktop studies, analysis of satellite imagery, mapping based on conceptual models or rules, etc.

- confidence that the mapped feature is a GDE - high, moderate or low.

A comparison of the attribution of GDE data in the original and updated Atlas is provided in Table 1.

Table 1. Comparison of the original and updated GDE attribution

\begin{tabular}{|c|c|}
\hline Original & Updated \\
\hline $\begin{array}{l}\text { 3. High potential for groundwater interaction } \\
\text { 4. Moderate potential for groundwater interaction } \\
\text { 5. Low potential for groundwater interaction }\end{array}$ & $\begin{array}{l}\text { 3. Potential GDEs identified in national assessment } \\
\text { - } \text { High potential } \\
\text { - } \quad \text { Moderate potential } \\
\text { - } \quad \text { Low potential } \\
\text { - Unclassified potential }\end{array}$ \\
\hline
\end{tabular}

\subsection{Engaging with GDE data custodians and data collection}

The next stage in the update was to identify recent GDE mapping datasets and to engage with the data custodians. This set the foundations for the update. As a starting point, the Bureau contacted GDE experts from the original Atlas project, which included members of the project team and the steering committee, along with representatives from each State and Territory. Through these stakeholders, the Bureau was able to identify recent GDE datasets available for each jurisdiction and the relevant data custodians. Nineteen datasets were identified in total (Table 2), which comprised 13 aquatic, 5 terrestrial and 1 subterranean datasets and covered parts of five States/Territories.

Table 2. State/Territory GDE datasets collected during the GDE update project

\begin{tabular}{|c|c|c|c|c|c|}
\hline State & Agency & Coverage & GDE Type & Currency & No. Datasets \\
\hline \multirow[t]{2}{*}{ QLD } & \multirow{2}{*}{$\begin{array}{l}\text { Department of Science, } \\
\text { Information Technology and } \\
\text { Innovation }\end{array}$} & Southern and central Queensland & $\begin{array}{l}\text { Aquatic } \\
\text { Terrestrial }\end{array}$ & Dec 2015 & 3 \\
\hline & & State & $\begin{array}{l}\text { Aquatic } \\
\text { Subterranean }\end{array}$ & Dec 2015 & 2 \\
\hline \multirow[t]{4}{*}{ VIC } & \multirow{3}{*}{$\begin{array}{l}\text { Department of Environment, } \\
\text { Land, Water and Planning }\end{array}$} & State & Aquatic & June 2015 & 1 \\
\hline & & $\begin{array}{l}\text { Goulburn-Broken and Gippsland } \\
\text { catchments }\end{array}$ & $\begin{array}{l}\text { Aquatic } \\
\text { Terrestrial }\end{array}$ & May 2015 & 4 \\
\hline & & Bungaree area, western Victoria & Aquatic & Nov 2009 & 1 \\
\hline & Melbourne Water & Melbourne region & Aquatic & Jul 2015 & 1 \\
\hline SA & $\begin{array}{l}\text { Department of Environment, } \\
\text { Water and Natural Resources }\end{array}$ & Lake Eyre Basin (SA portion) & $\begin{array}{l}\text { Aquatic } \\
\text { Terrestrial }\end{array}$ & Nov 2015 & 3 \\
\hline NT & $\begin{array}{l}\text { Department of Environment and } \\
\text { Natural Resources }\end{array}$ & State & Aquatic & $2010-2016$ & 1 \\
\hline NSW & Department of Primary Industries & State & Aquatic & July 2010 & 1 \\
\hline
\end{tabular}




\begin{tabular}{|l|l|l|l|l|l|}
\hline & - Water & North-eastern NSW & Terrestrial & Sept 2016 & 1 \\
\hline & & & & Total & $\mathbf{1 9}$ \\
\hline
\end{tabular}

The new regional scale GDE datasets were mapped using a range of approaches including field work (e.g. DEWNR 2015), remote sensing (e.g. DPI 2016) and GIS application of mapping rules (e.g. DSITI 2015). For example, the Queensland Government approach integrated local expert knowledge with remote sensing and other spatial datasets in a GIS to complete GDE mapping throughout the State. This work resulted in a complementary regional scale mapping method designed to capitalise on the availability of finer scale Queensland Government owned State-wide data sets and the wealth of information held by local and regional experts with significant understanding of landscape processes and ecosystems (DSITI 2015).

Since 2012, the Queensland Government has applied this mapping method to 55 catchments across Queensland covering over one million square kilometres including areas of major resource development (e.g. Galilee Basin, Surat Basin), significant river systems (e.g. Murray-Darling Basin), and areas of major growth (e.g. South East Queensland). In these areas, GDE mapping was completed mainly at a scale of 1:100,000, with some coastal areas completed at 1:50,000 scale. The attribution of GDE mapping data was also enhanced with information on why a particular ecosystem is mapped as groundwater dependent and the key characteristics of the relationship between the ecosystem and groundwater (DSITI 2015).

The Bureau then arranged teleconferences with the data custodian for each jurisdiction to describe the scope of the update project, find out more about the jurisdictional GDE mapping and arrange access to the datasets. Through this process the Bureau established strong, ongoing relationships with data custodians.

\subsection{Data integration}

The Bureau worked closely with data custodians to integrate their GDE data into the national Atlas dataset. The general approach to data integration is summarised in Figure 1. As each regional scale dataset was different, the approach was tailored to integrate each of them into the national dataset. The main integration steps were:

1. data review and consultation - analysing the new data to determine the appropriate method for integrating the mapping and attributes, which was then reviewed and endorsed by the data custodian

2. pre-processing - standardising the geometry and coordinate system of spatial data

3. attribution - applying the new attribution (refer to Section 2.1) to each GDE feature to identify GDEs as known or potential

4. mapping - integrating the new spatial data with the national dataset by replacing or merging

5. populating existing attributes in the national data model - with attributes from the new GDE datasets or using a Python script with attributes from national datasets e.g. land use, groundwater management areas.

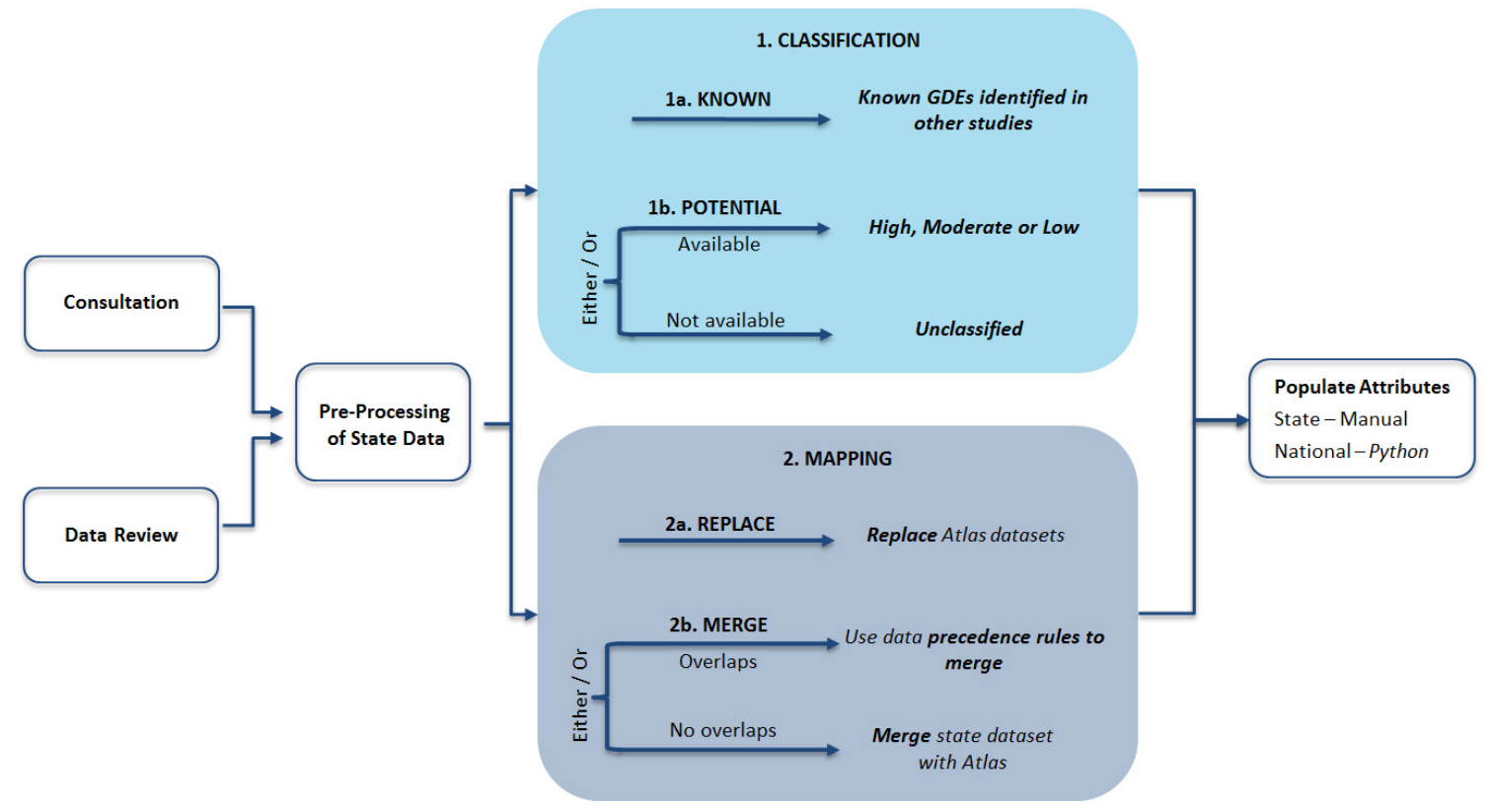

Figure 1. Approach to integration of regional scale GDE mapping into the national GDE dataset 


\subsection{Updating the web mapping application}

The new GDE data was then uploaded to the Atlas web application. The graphic design and functionality of the web application were updated to better align with user needs. A user survey was conducted to inform the update. Based on the results of the survey, users were seeking the following improvements to the application:

- functionality improvements, including improved search and download functions;

- better overall usability, with an improved toolbar, help menu and supporting documentation;

- cartographic refinement, including updated symbology;

- additional contextual layers, such as the location of bores and groundwater management areas; and

- $\quad$ an 'Areas of Update' layer which clearly conveys to users the regions where new data has been included in the Atlas.

\section{RESULTS - THE UPDATED ATLAS}

The new GDE data was successfully integrated with the original Atlas data to create updated national layers for Aquatic, Terrestrial and Subterranean GDE layers. As visible in Figure 2, the new attribution and symbology makes the data source, methodology and GDE confidence clear and upfront to users. The updated GDE layers have far more detail than the original GDE layers in some areas (Figure 2 inset) resulting in a significant increase in GDE features. Overall the number of GDEs in the Atlas has increased by $51 \%$ for Aquatic GDEs, by 53\% for Terrestrial GDEs and by 315\% for Subterranean GDEs.

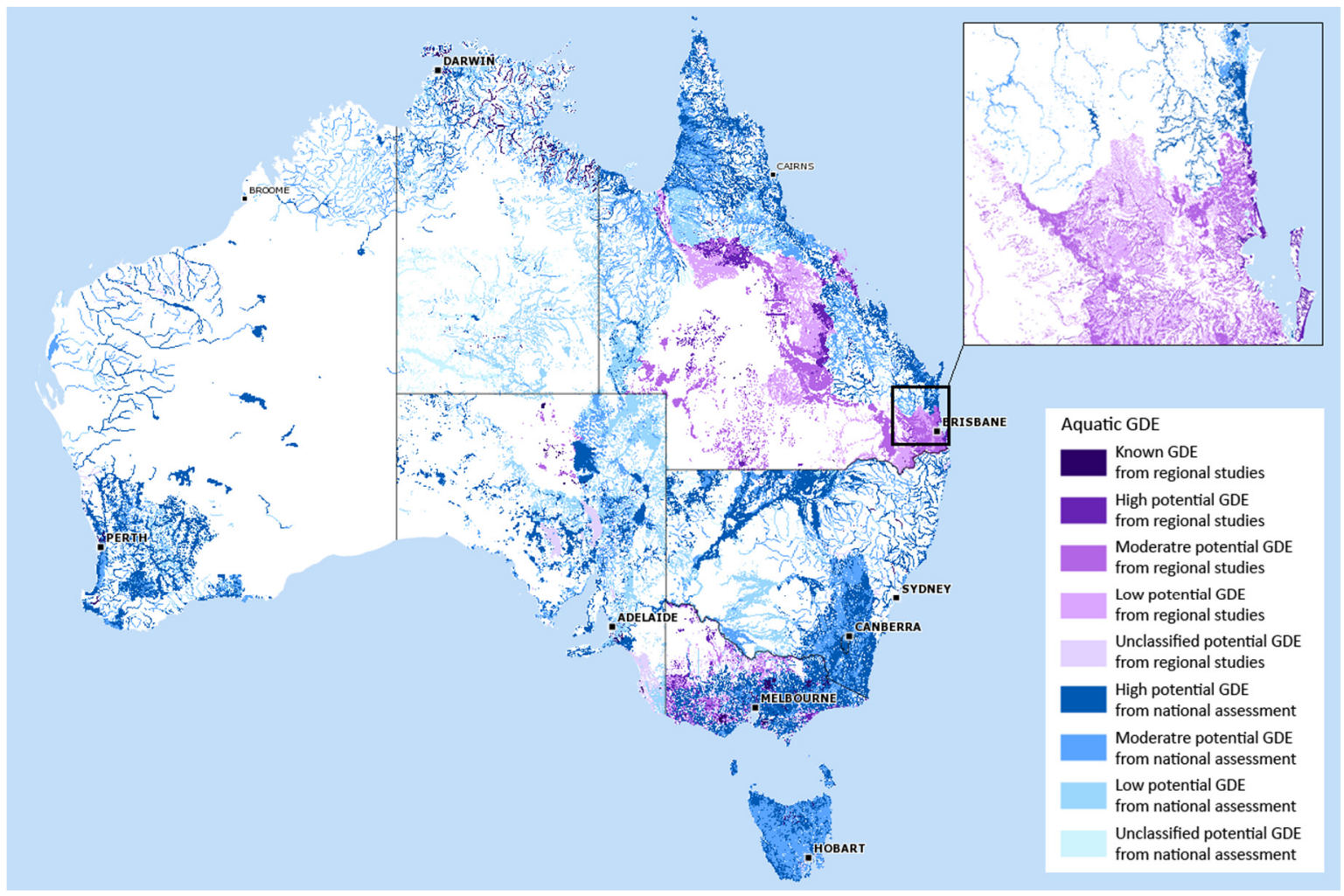

Figure 2. Updated Aquatic GDE layer with data from regional studies shown in purple and national assessment data shown in blue. Inset: region near Brisbane, Queensland, highlighting the additional detail in the regional studies.

The Atlas web application was updated with the new GDE data, as well as improvements to the graphic design and functionality to meet user requests (Figure 3). The updated Atlas is available from the Bureau website: $\underline{\text { http://www.bom.gov.au/water/groundwater/gde/map.shtml }}$ 


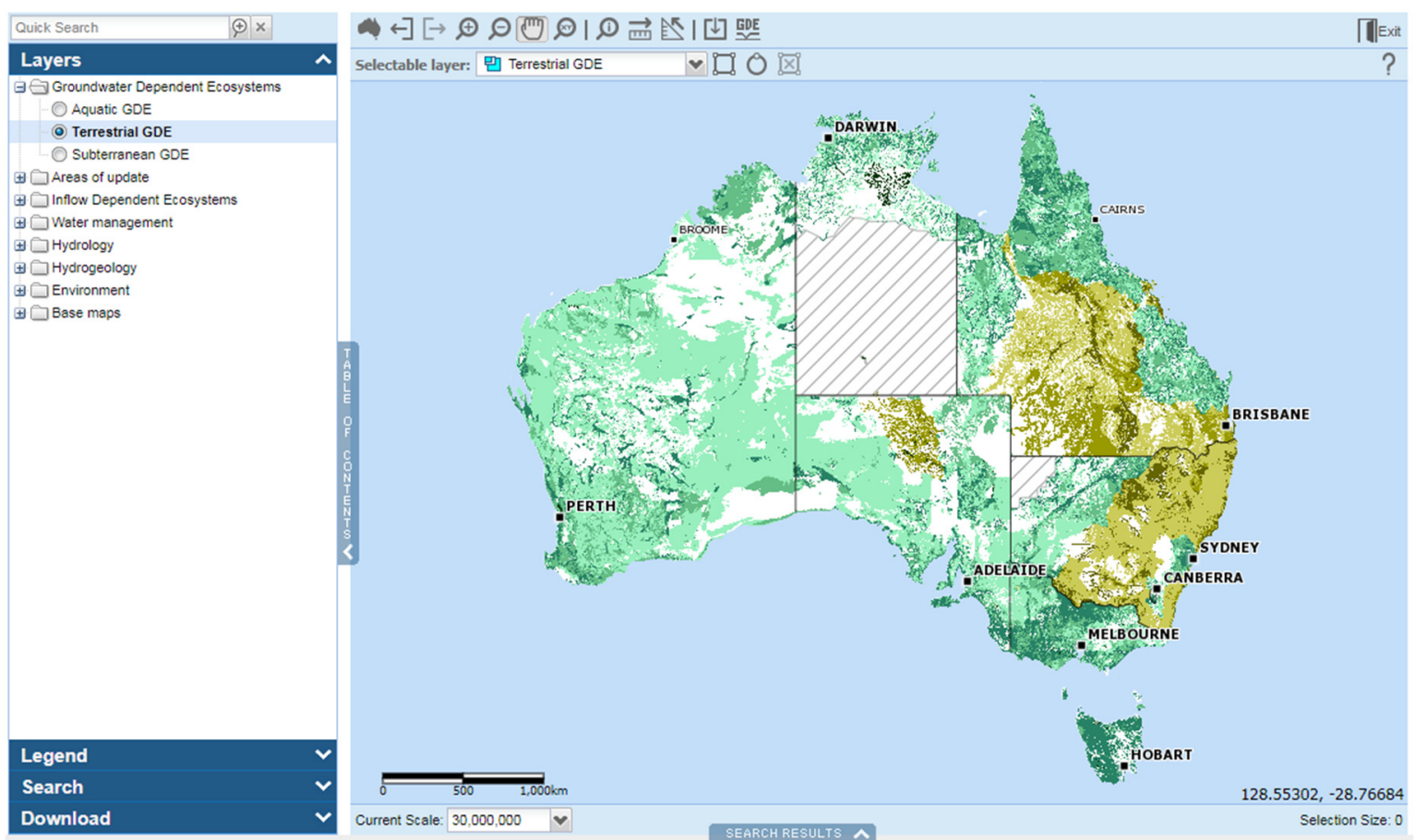

Figure 3. Screen shot of the updated Atlas web mapping application showing the updated Terrestrial GDE layer with data from regional studies shown in khaki and national assessment data shown in green.

The datasets in the Atlas are now updated, but new and improved datasets have already been produced by some States and Territories and this highlights the need for regular updates. The data is nationally standardised and available from a central location. It facilitates consideration of GDEs in decision making, such as environmental impact assessments and water management planning.

\section{BENEFITS OF A COLLABORATIVE APPROACH}

The approach to updating the Atlas by partnering with State and Territory data custodians has several benefits. Firstly, working closely with data custodians provides a link between the Bureau and State and Territory agencies, ensuring that the Bureau is aware of the most current datasets available and upcoming GDE mapping activities. Data custodians have expert knowledge of GDE features across their jurisdiction, and can provide valuable advice about suitable approaches to data integration, as well as detailed review of updated national datasets.

The approach also has advantages from a data custodian's perspective. From the Queensland Government's perspective, collaboration with the Bureau is critical to consistently deliver the best available information on GDEs to users across Australia. This is achieved through the periodic integration of Queensland's expanding coverage of GDE products into this single national dataset. Data is then is readily-available for users to efficiently access the best available information for any location in Australia. Since Queensland's GDE products are developed using the complementary catchment scale mapping method that includes expert consideration of the existing national dataset, integration into the national dataset uses a relatively simple replace method. Working closely with the Bureau into the future will continue to ensure that the best available GDE information is seamlessly delivered through both national and State platforms for use by Federal, State and local governments, natural resource management agencies, businesses, landholders and scientists in planning and managing the natural environment, developments and restoration.

Building on the success of the update, the Bureau has established a national GDE Reference Group to continue communication with data custodians, GDE experts and Atlas users. This group will facilitate ongoing access to updated GDE data in order to maintain the currency and relevance of this important groundwater product into the future. 


\section{REFERENCES}

Doody, T.M., Barron, O.V., Dowsley, K, Emelyanova, I. Fawcett, J., Overton, I.C., Pritchard, J.L., Van Dijk, A.I.J.M. and Warren, G. (2017) Continental mapping of groundwater dependent ecosystems: A methodological framework to integrate diverse data and expert opinion, Journal of Hydrology: Regional Studies Volume 10, April 2017, Pages 61-81: http://www.sciencedirect.com/science/article/pii/S2214581817300319

DEWNR (2015) Lake Eyre Basin Springs Assessment: SA Data Management, DEWNR Technical report 2015/49, Government of South Australia, through Department of Environment, Water and Natural Resources, Adelaide.

DPI (2016) Methods for the identification of high probability groundwater dependent vegetation ecosystems. Department of Primary Industries.

DSITI (2015) Queensland Groundwater Dependent Ecosystem Mapping Method: A method for providing baseline mapping of groundwater dependent ecosystems in Queensland. Department of Science, Information Technology and Innovation http://wetlandinfo.ehp.qld.gov.au/resources/static/pdf/factsmaps/gde/queensland-gde-mapping-method-v11-070515.pdf

Eamus, D., Froend, R., Loomes, R., Hose, G., and Murray, B. (2006) A functional methodology for determining the groundwater regime needed to maintain the health of groundwater-dependent vegetation. Australian Journal of Botany 54:97-114. doi:10.1071/BT05031

Foster, S. and Tyson, G. (2016). Ecosystem Conservation and Groundwater, International Association of Hydrogeologists, Strategic Overview Series: https://iah.org/wp-content/uploads/2016/04/IAH-SOSEcosystem-Conservation-Groundwater-9-Mar-2016.pdf

Richardson S, Irvine E, Froend R, Boon P, Barber S, Bonneville B (2011) Australian groundwater-dependent ecosystems toolbox part 1: assessment framework, National Water Commission, Canberra.

SKM (2012) Atlas of Groundwater Dependent Ecosystems (GDE Atlas) Phase 2 Task 5 Report: Identifying and mapping GDEs, report produced for the National Water Commission, Canberra.

SKM and CSIRO (2012) Atlas of Groundwater Dependent Ecosystems (GDE Atlas) Phase 2 Task 4 Report: Mapping Inflow Dependency from remote sensing, report produced for the National Water Commission, Canberra. 